\title{
ORGANIZADOS PARA NO LEER
}

Gabriel Zaid*

L a esencia de la vida literaria está en leer, que es una actividad mental y solitaria, aunque puede vivirse como un diálogo, hasta con cierta animación corporal. Por esto, como señaló Vasconcelos, hay libros que se leen de pie; libros que nos mueven a hacer cosas, tomar notas, consultar un diccionario, ver el jardín con otros ojos.

Por esto, también, una extensión normal de la vida literaria es compartir esa animación hablando de la experiencia de leer, de lo que dice el libro y cómo lo dice, de lo que gusta o decepciona. Ese diálogo estimulante puede extenderse a la actividad de escribir, también mental y solitaria, dialogal, animada, ambulatoria.

Hay muchas extensiones de la vida literaria. Algunas tan indirectas que no requieren la lectura. Algunas tan ajetreadas que no dan tiempo de leer. Paradójicamente, las actividades que pueden prosperar sin necesidad de leer han llegado a ser vistas como "la vida literaria".

1. Conocer nombres de autores y de libros en cápsulas informativas y valorativas de enciclopedias, solapas de libros, cubiertas de discos, letreros de museos, programas de espectáculos, anuncios, noticias, entrevistas, frases o juicios escuchados. Información valiosa para alternar en la conversación, orientarse y elegir, porque no hay tiempo de leer todo, y las noticias pueden funcionar como lectura previa, en muchos casos más que suficiente.

2. Conocer libros por la encuadernación, la tipografía, las ilustraciones. Mejor aún, tenerlos en opulentas bibliotecas, para sentirse

* Escritor y ensayista. Miembro de E1 Colegio de México y de la Academia Mexicana de la Lengua. El artículo fue publicado en Letras Libres en mayo de 2002. Se publica con las autorizaciones correspondientes. Fecha de recepción: 2 de marzo de 2015, fecha de aceptación: 29 de abril de 2015. Sugerencia de citación: Zaid, G. "Organizados para no leer", Revista de Economía Institucional 17, 32, 2015, pp. 377-383. DOI: 10.18601/01245996.v17n32.13 
acompañado y enseñarlos, así como fotos, bustos, ediciones firmadas y otras reliquias de autores eminentes. Objetos que dan calor (no solo prestigio) cultural, que decoran, ambientan, embellecen, y que no hace falta leer.

3. Conocer autores por la encuadernación social. Estar al día de chismes literarios, artísticos, culturales, con todas sus ramificaciones sociales, sexuales, conflictivas, de fama, de poder, de fortuna. Mejor aún, tratarlos personalmente y de tú, en reuniones que pueden conducir a una familiaridad de muchos años, aunque no necesariamente a la lectura.

No faltan tímidos que se avergüenzan de estar en una cena de homenaje a un autor, por su reciente libro, sin haberlo leído. Pero la gente más mundana sabe que lo importante es el brindis, la alegría, el sentirse parte de una comunidad culta, las sabrosas ocurrencias y chismes de la celebración: lo que dice la fiesta, no lo que dice el libro.

Tampoco faltan inocentes que dan excusas por lo caro que están los libros, lo difícil que es conseguirlos (no lo tuvieron en cuatro librerías) y la falta de tiempo para leer; aunque el libro cueste menos que la cena, y leerlo tome menos horas que reunirse, celebrarlo y volver a casa.

Lo importante de las reuniones son las reuniones, no los libros, aunque se hagan con el pretexto de los libros. Lo importante de tratar a los autores es tratarlos, no leerlos. Convivir con el establishment. Dejar caer, como no queriendo, la alusión que provoca la sorpresa: Pero... ¿lo conoces?

4. Organizar actos públicos de presentación de autores y libros. Suelen ser menos divertidos que las cenas privadas, pero más democráticos: la entrada libre es una oportunidad para los no invitados a las cenas. Ahí está, lo pueden ver, quizá hasta dirigirle una pregunta. Pueden sentir que forman parte de la vida literaria. Quizá (aunque el porcentaje no es muy alto) animarse a comprar sus libros, sobre todo si los firma con amables dedicatorias. Pero si fuera posible saber cuántos leyeron el libro, antes o después del acto, y no solo del público (escaso, pero admirable, frente a las peripecias de llegar a tiempo), sino de los mismos organizadores y presentadores, quedaría claro para qué es el acto.

Lo importante de la presentación de libros es la presentación, no la lectura. Lo importante es el montaje teatral de un acto que sirve para adquirir presencia en la vida social, pagando anuncios y generando noticias en los periódicos, la radio y la televisión. Para lo cual es innecesario que los participantes hayan leído el libro o piensen leerlo. Basta con que se difunda la manifestación de que el libro existe, el 
autor existe, la editorial existe, los distinguidos oficiantes del acto y la institución que lo cobija existen, en beneficio de todos ellos. Lo importante es lo que dice el acto, no lo que dice el libro.

5. Promover el periodismo cultural. Los diarios de la ciudad de México publican en conjunto más páginas culturales que los de Nueva York o París. Se trata de un fenómeno relativamente reciente, que en el primer momento pareció un avance, y lo es: para todo lo organizado en función de no leer. Las páginas culturales hacen resonar los nombres de los autores, libros, instituciones; para lo cual bastan los encabezados y las fotos, sin necesidad de leer, ya no digamos los libros, sino los artículos de las páginas culturales, por lo general sin interés. Lo importante es el tamaño de los encabezados, la asignación de espacio, de lugar, de color: lo que dice el editor, destacando o relegando; no lo que dicen los textos, muchos de los cuales son simples glosas de anuncios, invitaciones, solapas y boletines de relaciones públicas. En las páginas culturales no abundan los artículos inteligentes y bien escritos de un autor que ha leído a otro, que sabe de lo que está hablando y opina con sinceridad.

Cuando no había docenas de páginas culturales diarias, sino unos cuantos suplementos semanales, las mejores plumas hacían comentarios de libros, y los jóvenes talentosos se disputaban el privilegio de alternar con los consagrados, escribiendo reseñas mal pagadas en dinero, pero bien pagadas con abundantes libros que les permitían leer, leer, leer. Desgraciadamente, las mejores plumas consagradas y juveniles no se multiplicaron por veinte o treinta, cuando las páginas culturales se multiplicaron por veinte o treinta. Para llenar tantas páginas, llegaron los universitarios que estudiaron comunicación, tan atiborrados de clases sobre cine, televisión, radio, periódicos y revistas; tan conscientes de que los nuevos medios son un avance sobre el libro, y está en curso una mutación hacia la imagen; tan absorbidos por el ajetreo del acontecer, que no tienen tiempo de leer.

¿Cómo pueden jerarquizar los acontecimientos literarios aquellos que no leen? Dando por supuesto que el verdadero acontecimiento no sucede en el texto milagroso, sino en los actos sociales que lo celebran. Jerarquizando socialmente, como se jerarquizan las bodas, las solemnidades oficiales, el lanzamiento de nuevos productos; no literariamente, como se jerarquizan los textos maravillosos o decepcionantes. Si el texto maravilloso se publica sin ningún ruido social, no es noticia para la prensa, aunque la noticia corra de boca en boca entre los que sí leen. Por el contrario, un texto decepcionante, pero firmado, publicado, presentado, por personas e instituciones con poder 
de convocatoria social, sale en los periódicos y en la televisión, aunque la decepción corra de boca en boca entre los que sí leen.

Es posible que el ruido en los medios sea la extensión de lo que corre de boca en boca, pero no es necesario. En primer lugar, porque el ruido suele ser positivo. El aparato cultural no hace ruido para decir que se equivocó. Pero, sobre todo, porque el ruido no necesita la lectura. Puede empezar de cualquier manera (por la amistad, el accidente, la promoción de los interesados) y, a partir de ahí, reverberar de unos medios a otros. ¿Cómo jerarquizan los periódicos a los autores? Por el espacio que les dedican los otros periódicos. Por su presencia en la radio y la televisión. Por los puestos que tienen, sobre todo en el aparato cultural. Por las solapas de los libros y los boletines de prensa. En los cielos de la buena prensa, lo que hace ruido sonará más; y lo que suena poco será silenciado.

Pero, ¿dónde acontece la vida literaria sino en la página leída? De ese acontecimiento, casi no hay nada en las páginas culturales. No es noticia, no es chisme, no es imagen fotografiable. Además, toma tiempo. Es más rápido entrevistar a un escritor que leer sus libros. En cierta forma, es como haberlo leído en un rato y amenamente, en vez de pasarse horas, días y semanas leyéndolo. Es como invitar al público a las cenas íntimas del establishment. Más aún, si el entrevistador logra colarse hasta las recámaras de lo inédito, con el periodismo Mata Hari: fingirle amor al entrevistado, hasta sacarle una declaración que lo hunda.

El periodismo cultural se ha vuelto una extensión del periodismo de espectáculos. Lo importante son los titulares, las fotos, las entrevistas y los chismes de las estrellas, para estar al día y tener de qué hablar como persona culta, sin necesidad de leer.

6. Dar premios y distinciones. La gente con experiencia en juntas de trabajo sabe qué fácilmente se puede participar sin haber hecho la tarea; qué peligroso es suponer que todos leyeron y estudiaron la documentación necesaria para votar y decidir. Lo mismo sucede en las sesiones para elegir nuevos miembros de doctas academias, conceder honores, distinciones y premios, sin leer.

Para simplificar, ignoremos los casos donde pesan mucho los intereses extraliterarios, porque entonces, por definición, sale sobrando leer la obra. Son más significativos los casos inocentes: aquellos donde, sin presión alguna, los jurados se enfrentan a responsabilidades inhumanas. Si la persona es un encanto en las cenas, si sale en los periódicos y la televisión, si tiene buen currículo (es decir: si los jurados anteriores hicieron su tarea y dieron su aprobación), si me han habla- 
do de sus muchas cualidades, es absurdo que, en este mal momento, deje todas mis tareas pendientes para ponerme a leer sus libros y los de todos los demás candidatos. Así se vota de oídas, ateniéndose al trabajo de los que hicieron su tarea. Claro que si nadie la hizo, y los jurados anteriores tampoco, los resultados pueden ser vergonzosos: ignorar obras valiosas que no fueron leídas; encumbrar a mediocres que no han sido leídos; multiplicar los intereses creados a favor del ruido, no la lectura.

Para corregir estos errores y omisiones del canon, hacen falta lectores denodados, con talento, valor civil y muy buena suerte, porque, una vez consagrada una obra mediocre, una vez que la avalan personas e instituciones de peso, no es razonable esperar que se desdigan; lo razonable es suponer que el contradictor lee torcidamente, por ineptitud o motivos inconfesables. En 1918, ¿quién se hubiera atrevido a pensar, ya no digamos a decir, que un poeta celebrado por José Vasconcelos y Carlos Pellicer, prologado por Rafael López y Antonio Castro Leal, comentado en The Saturday Evening Post y The New York Times Review, no tenía importancia por sus textos, sino por el ruido que los acompañaba? Para ganar esa batalla absurda, hubiera tenido que ponerse a leerlo en serio, estar dispuesto a refutar el consenso favorable, tomarse todos los trabajos del caso y encontrar apoyo para sus opiniones. Algo tan pesado, improbable y sospechoso como conseguir presupuesto, ayudantes, laboratorios, para refutar los experimentos científicos de un premio Nobel. Hoy que ya no se habla de Pedro Requena Legarreta, menos aún hay quien lo lea. Pasó de ser famoso, sin ser leído, a quedar descartado, sin ser leído.

7. Estudiar letras. Alguna vez, Huberto Batis relató una experiencia deprimente. Dando clase en el último año de letras, tuvo una sospecha que lo obligó a preguntar: ¿Cuántos de ustedes han leído a López Velarde? Silencio general, y una sola mano que se alza, con explicaciones desoladoras: vínculos familiares en la tierra natal del poeta... En otras disciplinas y países se cuentan cosas semejantes. Una notable (porque revela cómo el mundo académico se ha vuelto burocrático, y tiende a modelarse en la figura del ejecutivo, no del lector) empieza con la extrañeza de un director de tesis ante cierta afirmación: ¿Cómo puede decir tal cosa, si su bibliografía incluye tal libro? ¿Lo leyó realmente? Breve respuesta ejecutiva: No personalmente.

La mala prosa en las ciencias sociales se ha vuelto casi un requisito (los historiadores, sociólogos, psicólogos que escriben demasiado bien se vuelven sospechosos de poca profundidad). Pero en los trabajos literarios es una contradicción. La mala prosa sobre las bellas letras 
demuestra poco entendimiento del juego literario, incapacidad de lectura de los textos propios y ajenos. Demuestra que lo importante es el juego académico, no el literario. El gusto, la malicia, la pasión de leer, son loables, pero no hacen falta para acumular puntos curriculares.

8. Publicar libros. Un excelente editor holandés, Carlos Lohlé, me contó alguna vez cómo ascendió de alto ejecutivo de una editorial europea a editor marginal en Buenos Aires. La trasnacional se metió en problemas publicando un libro que traía barbaridades imperdonables. Se hizo una investigación a fondo en todos los departamentos y resultó que nadie lo había leído. Pero, ¿cómo podemos publicar libros que no leemos? Porque no estamos organizados para leer, sino para alcanzar metas de crecimiento, producción, ventas, rentabilidad. Si yo leyera personalmente todos los libros que publico, ¿cuántos podría publicar? Poquísimos, porque tengo que leer diez para publicar uno; y, si no tengo tiempo de leer más que dos o tres por semana, no puedo publicar más que uno al mes. Admirablemente, Lohlé aceptó sus conclusiones y renunció, para poner una editorial donde pudiera responder de cada libro como lector, no como ejecutivo que confiesa: ¿Lo leíste? No personalmente.

No hace falta decir que sus cuentas valen para todo el mundo del libro: lectores, libreros, bibliotecarios, promotores, distribuidores, editores, periodistas, críticos, profesores, investigadores, autores. Y que todas las aberraciones derivan de esa realidad aplastante: no se puede leer tanto. Para que la máquina siga andando, tiene que organizarse en función de que leer es bonito, y muy recomendable, pero no necesario.

Para opinar en una cena de las últimas novedades literarias, intelectuales, artísticas, dando por supuesto y ya leído todo lo anterior, desde los clásicos, hay que tener noticias, no lecturas. Para leer todo lo que publican las personas que conocemos, hay que dejar todo, y dedicarse nada más a eso; o romper con la sociedad y vivir en el desierto; o no leer, sino tratar a los autores, y conocer sus libros por los títulos, las solapas, las entrevistas, los premios y distinciones. No lo pueden tomar a mal, porque ellos hacen lo mismo. En el mutuo envío de libros, lo importante es la participación de boda o de bautizo: lo que dice el gesto de acordarse de un amigo o conocido, no lo que dice el libro.

Hasta llega a haber casos en que ni los autores han leído lo que publican. Sucede con algunos personajes ocupadísimos, pero deseosos de firmar libros. Sucede con los libros de ponencias que no escucharon ni los otros ponentes y nadie leerá, porque se imprimen para aumentar el capital curricular de los participantes y las instituciones. $\mathrm{O}$ por el ancho mundo del non-book, organizado y producido (dirigiendo el 
trabajo de ayudantes), más que escrito. $\mathrm{O}$ con algunos escritores prolíficos que escriben sin parar y sin leerse, algunos nada mal. Cuando aparecieron las computadoras personales, le regalaron una a Isaac Asimov (autor de cientos de libros), pensando que lo celebraría mucho. Los decepcionó: Está bien para los que reescriben. Yo prácticamente no corrijo. Y como mi tecleo en computadora no es más rápido que en máquina de escribir, produje lo mismo.

Cuando Brezhnev presidió el Soviet Supremo, publicó un libro traducido a docenas de idiomas, presentado en multitud de mesas redondas y reseñado elogiosamente en todo el planeta, aunque es posible que no lo leyeran ni él, ni sus editores, ni sus presentadores y comentaristas. Muchos libros costosísimos que publican las grandes empresas para celebrarse a sí mismas, o como regalo de Navidad, siguen el mismo camino: de la celulosa convertida en papel impreso al papel impreso convertido en celulosa. Pero no importa. En los circuitos del aparato resonador, lo importante es que la celulosa reciclada una y otra vez genere resonancia, no lectura.

Algunos monjes creen que la oración sostiene el mundo. Que si todo no revierte a la nada es porque nunca faltan almas piadosas que rezan desde el fondo de su corazón. Creamos, inocentemente, que si el mundo del libro no se reduce a la circulación de celulosa, es porque nunca faltan lectores de verdad. 